Short Report

\title{
Neuromuscular Blocking Properties of Some Antibiotics in Man
}

\author{
Yasuhiko Hashimoto, Takeshi Shima, Shuh Matsukawa \\ and Kenichi Iwatsuki \\ Department of Anesthesiology, Tohoku University School of \\ Medicine, Sendai
}

Hashimoto, Y., Shma, T., Matsokawa, S. and Imatsuki, K. Neuromuscular Blocking Properties of Some Antibiotics in Man. Tohoku J. exp. Med., 1975, 117 (4), 399-400 Neuromuscular blocking properties of ribostamycin (1 $\mathrm{gm})$, dibecacin (100 $\mathrm{mg}$ ) and tobramycin $(60 \mathrm{mg})$ were studied in man during anesthesia and surgery by observing the effects of these antibiotics on muscle twitch tension. These drugs alone did not show any neuromuscular blocking action in those therapeutic doses. However, during the recovery phase of d-tubocurarine block the intravenous administration of $1 \mathrm{gm}$ of ribostamycin caused a fairly rapid decrease in twitch tension. Tobramycin $60 \mathrm{mg}$ did not show any remarkable effect, but dibecacin $100 \mathrm{mg}$ produced a slight potentiating effect on the action of d-tubocurarine. The enhancement of the action of dtubocurarine was antagonized promptly by edrophonium and more slowly by calcium. ribostamycin; dibecacin; tobramycin; neuromuscular blocking property

Respiratory arrest following the intraperitoneal administration of neomycin under ether anesthesia was first reported by Pridgen in 1956. Since that time other antibiotics of aminoglycoside and polypeptide structures (kanamycin, streptomycin, polymyxin $B$ and colistin) have been similarly implicated. The purpose of the present study is to determine the neuromuscular blocking properties of ribostamycin sulfate (vistamycin ), debecacin sulfate (panimycin) and tobramycin (nebramycin factor 6) in therapeutic doses in man.

\section{Methods}

Twelve adult patients, who were to undergo genito-urinary surgery, were studied during anesthesia and surgery. The patients were premedicated with meperidine and atropine one $\mathrm{hr}$ prior to anesthesia. After peridural analgesia, general anesthesia was induced with thiamylal sodium and maintained with nitrous oxide and oxygen. Prior to the study the patients' forearm and hand were fixed firmly to a specially designed metal armboard.

The median nerve was stimulated at the elbow indirectly through the subcutaneous needle electrodes with supramaximal stimuli using an electric stimulator (Nihon Kohden SEN-1101). The stimuli were square-pulses of $0.2 \mathrm{msec}$ duration and 25-65 volts in intensity and were delivered at a frequency of $0.2 \mathrm{~Hz}(12 / \mathrm{min})$. The resultant force of adduction of the middle finger was recorded by a force-displacement transducer connected to a recorder (Nihon Kohden multipurpose polygraph). When a steady twitch height was obtained, ribostamycin $1 \mathrm{gm}$, debecacin $100 \mathrm{mg}$ and tobramycin $60 \mathrm{mg}$ were given

Received for publication, August 19, 1975. 


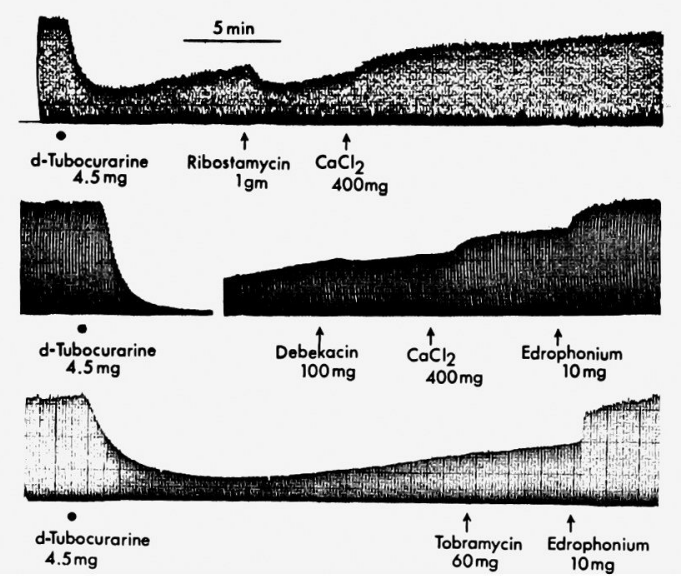

Fig. 1. Continuous tracings of the effects of antibiotics on the action of d-tubocurarine. Upper trace: effect of $\mathbf{l} \mathrm{gm}$ of ribostamycin and calcium reversal of blockade. Middle trace: effect of $100 \mathrm{mg}$ of debecacin. Calcium and edrophonium were effective to reverse the block. Lower trace: effect of $60 \mathrm{mg}$ of tobramycin.

intravenously and their effects on muscle twitch were observed. These drugs were also given during the recovery period from d-tubocurarine block to determine the interaction of these drugs with d-tubocurarine.

\section{Results}

No change was observed in twitch height when these antibiotics were given intravenously in therapeutic doses. However, the intravenous injection of $1 \mathrm{gm}$ of ribostamycin caused a fairly rapid decrease in twitch height which had recovered to 50 to 60 per cent of the control level from d-tubocurarine block (Fig. upper trace). Debecacin $100 \mathrm{mg}$ also produced a slight potentiating effect on partial d-tubocurarine block, but $100 \mathrm{mg}$ of tobramycin did not show any discernible effect (Fig. middle and lower traces). The enhancement of the action of d-tubocurarine by these antibotics was antagonized promptly by edrophonium and more slowly by calcium (Fig. 1).

Generally, the dosages of antibiotics necessary to produce neuromuscular block greatly exceed the therapeutic ranges. Several situations, however, may produce possible neuromuscular blocking effect due to excessive blood concentrations of antibiotics or due to their interaction with non-depolarizing muscle relaxants. Since the major excretion route of antibiotics is urinary, renal failure may increase the blood levels of antibiotics. The neuromuscular blocking effect is expected to be more pronounced in a patient with myasthenic state or as a result of rapid absorption of the drugs following the intraperitoneal or intrapleural instillation. Although both calcium and neostigmine (or edrophonium) counteract the neuromuscular blocking effect of antibiotics, maintenance of an adequate ventilation should be mandatory until spontaneous respiration becomes adequate.

\section{Reference}

1) Pridgen, J.E. (1956) Respiratory arrest thought to be due to intraperitoneal neomycin. Surgery, 40, 571-574. 